\title{
FRAMING TOURIST RISK IN UK PRESS ACCOUNTS OF HURRICANE IVAN
}

\section{Introduction}

Hurricane Ivan, dubbed 'Ivan the Terrible' wreaked havoc and caused much terror in its approach and actual landfall on the Caribbean basin and the southern US state of Florida. A category 5 hurricane packing winds of some 160-190 miles per hour, Hurricane Ivan posed a threat of cataclysmic proportions to a region that was already haunted and weary from a prolific succession of hurricanes that season. However, Hurricane Ivan was not a no-escape natural disaster as defined by Huan, et al (2004) where there was no lead-time to escape, as in the case of an earthquake with limited prior warning to activate emergency and disaster prevention controls. They state that an 'escapable disaster is when it is possible to inform locals and tourists of well-planned escape or fail-safe protection measures before the disaster hits'. With Hurricane Ivan there was time for locals to erect storm shutters, for disaster management agencies to advise people to evacuate from vulnerable areas, and to implement other safety measures on the ground. Within the tourist sector, there was also sufficient time to arrange emergency airlift for tourists, and for hotels to activate their disaster management plans to ensure the safety of their guests.

The possibility of early warning systems for natural disasters therefore provides opportunities for well-planned management frameworks that facilitate proactive implementation of measures to mitigate the overall loss of life (Faulkner, 2001). It also allows the establishment of communication links and systems to disseminate, monitor and control the nature of information that is sent regarding the negative event. According to Huan et al (2004), proactive disaster communication and media strategies may reduce the protracted coverage of negative events by proving timely information to lessen the perception of 'volatility and danger' in affected areas. Particularly for vulnerable industries such as tourism where risk perception tends to influence travel choices and behaviour, the extent to which communication strategies in the aftermath of a negative event are able to mitigate perceptions of upheaval and chaos, may determine the pace of recovery and restoration to normality (Avraham and Ketter, 2008; Henderson, 2007; Reisinger and Mavado, 2005). 
The tourism disaster management literature has addressed the strategic role of the media in pre and post disaster management with specific prescriptions on how to relate to and engage the media in the process of recovery (Avraham and Ketter, 2008; Bierman, 2003). Particularly for tourism destinations, media reporting of disasters may influence the image of these countries in key tourism generating markets (Law: 2006). The effectiveness of tourism recovery strategies post disasters may be mediated by the extent to which the media responds to messages from official destination sources. Media sources selected for information on disasters are key indicators of their news values and point to the spokespersons and organistions that they deem to be most credible. The extent to which these news stories are framed in terms of the perspectives of official sources that are responsible for the management of the crisis and the reduction of visitor risk, may be an effective gauge of the destination's tourism crisis media management strategies.

The purpose of this study is to examine press accounts of Hurricane Ivan when it made landfall on the Caribbean and Florida in September 2004. It examines how the events of the disaster were framed with specific focus on how tourist risk was constructed in these press reports. The aim of this enquiry is to determine media values in terms of their use of main sources for information, and aspects of the disasters that they deemed to be most salient in terms of their headlines and lead sentences.

This investigation will therefore examine how tourist risk was constructed based on these key characteristics of the coverage in the wake of Hurricane Ivan, where there was sufficient lead-time for disaster managers in affected areas to establish clear communication links, and to provide the media with authoritative updates. Overall, this enquiry seeks to address the research question: 'To what extent did press accounts of Hurricane Ivan in the UK amplify or attenuate tourist risk in their reports of the crisis?'

The next section of this paper reviews the key theories in relation to media practices in reporting risk events. It also highlights the key variables that are pertinent in assessing and measuring risk attenuation and amplification by the media. The implications of media reports and travel decision processes are examined as well as the risk and crisis 
management strategies that are vital at the onset and through the course of the crisis event to mitigate negative outcomes.

\section{Social Amplification of Risk Framework (SARF)}

In a paper on media reporting on risk in the UK between 1992-1995, Smallman (1997:161) found that there was 'a steadily rising trend' of such accounts representing a yearly growth rate. He noted that this trend in the UK reflected a comparable growth of worldwide media reports on the subject. Smallman contended that the rise in media reports on risk may be attributed to several factors such as the 'quest for sensationalism by the media' as well as improvements in reporting aided by rapid advances in information and communication technologies. However, he also argued that this rising trend in media reporting of 'risk' events may be indicative of a world that is becoming a 'riskier and more uncertain place'.

While it may be arguable whether the continuous growth of media reporting of risk is contributing to a greater level of individual perception of risk, it could also be contended that the cognitions, views and perceptions of risk that people hold are often shaped by how these events are mediated and represented. According to Smallman and Weir (1999:36), the communication and dissemination of information related to a crisis event involve a process of 'appropriate recruitment, selection, training and socialisation'. The individual's conception of risk is therefore socially constructed and so information and communication are of crucial importance in relation to 'risk related behaviour'.

The social amplification of risk framework (SARF) helps to clarify how perceptions of risk are formed (Pidgeon et al, 2003). It proposes that when a crisis or disaster occurs, a signal value is produced. Individuals or groups interested in or related to the risk are likely to filter or distort the signals based on their own beliefs and values (Kasperson, and Kasperson, 2005). In this respect, the model accounts for the 'perceptual gaps' that may exist between various stakeholders in their perception and assessment of a crisis. However, Smallman and Weir (1999) caution that this model does not address the link between perception and action. In other words, it is difficult to predict specific actions or behaviour only on the basis of the individual's assessment of risk. 
However, the model of social amplification of risk is useful in clarifying how the media works in relation to shaping the views and perceptions that individuals may have concerning risk associated with a disaster or crisis (Rickard et al, 2013). On many occasions the public has to rely on media reports for information during and after a catastrophic event, particularly when there are no credible alternative sources of information. In this regard the media is a key player in the recovery process. Milo and Yoder (1991) state that inaccuracies in media reporting not only impede short-term recovery strategies for tourist destinations, but may also create longstanding negative images of these countries and regions. Inevitably the media will amplify or attenuate and so distort the event being covered as they engage in activities to gather information from various sources, make judgements on what would be the particular interests of their readers, engage the widest possible audiences, and to outperform their competitors for the highest readership in the market.

\section{Framing in the Mass Media}

The examination of media coverage of disasters and crisis may serve to illustrate how they frame these events in their quest to represent the perceived reality of events. Santos (2004:123) observes that mass mediated products such as newspaper accounts utilise the practice of framing in the coverage of news stories. She argues that to frame is to select certain issues and to make them more salient in order to present a particular angle that 'influences meaning making'. Framing therefore involves the process of making meaning by emphasising particular aspects and deleting those parts that may not be considered important. Frame analysis of media coverage provides insights into how meanings are socially constructed and uncovers how shared meanings and myths are produced and reproduced in societies. Santos maintains that since 'news media accounts are used by audiences to construct their own themes to understand social issues', the framing practices of the media is a key indicator of the dominant ways of constructing meaning and patterns of 'cognition, interpretation and presentation'.

In her study of representations of Portugal in four selected American newspapers, Santos (2004) found that the mass media presented messages on Portugal as a tourist destination that were not 'culturally neutral'. She concludes that: 
When the mass media transmit a message about a specific region of the world, they ultimately replace the specific values of those whom they are reporting about with the values of those to whom they are reporting. This forcing of destinations into the context of the reader present him/her with his/her own views.

It may be argued that this representational practice is also pertinent to the coverage of disasters and crises by the media. This means that the coverage of disasters as they occur across the world are likely to be framed within the context of the shared meanings and values of the audiences that are the targeted consumers of the reports. In this regard, the social amplification of risk framework is again relevant in accounting for the perceptual gaps that may occur between various groups related to the crisis or disaster. This poses complex challenges to persons manning command centres and the flow of information during crises situations particularly when the media draws from sources that provide different perspectives and assessments than those that emanate from official disaster management control centres.

\section{Crisis and Emergency Risk Communication Framework (CERC) \& Media Management}

The literature on crisis and disaster management provides some prescriptions on how to manage the media in crises situations (Avraham and Ketter, 2008; Bierman, 2003; Faulkner, 2001; Glaesser, 2003; Gonzalez-Herrero and Pratt, 1998; Greg et al, 2002; Lungren \& MacMakin, 2013; Ritchie, 2004; Stafford et al, 2002). Zerman (1995:26) for example, sets out a ten-point guide for an effective crisis communication programme for working with the media. According to Zerman (1995) the key issue is to ensure the centralisation of information dissemination and interaction with the media with the setting up of a proper media centre as is conveniently possible. Of crucial importance is to designate a principal spokesperson and a back-up person who have media credibility to present official information. He also emphasises the importance of being prompt and in treating all media agencies equally with information. In other words, cherry picking selected media outlets for exclusives should be discouraged.

Zerman (1995) notes that disaster managers should also allow the media access to the disaster area as is possible. Post Hurricane Ivan, Cayman Island officials adopted a policy to restrict the entry and movements of all persons (BBC, 2004). The negative outcome of this decision was that media reporters were unconvinced that this action was motivated by the exigencies of the disaster, and reported that the island officials 
were engaged in a cover-up of the extent of the hurricane damage in order to protect their lucrative financial and tourism sectors. Henderson (202:284) supports the view that the media should be allowed access and room to cover events and that it is advisable to integrate them in the process of recovery management. She notes that media exclusion or non-cooperation is rarely advised because it implies evasion and is likely to result in unfavourable coverage.

An indicator of the effectiveness of media communication strategies according to Milo and Yoder (1991:39), is the extent to which the media's support is engaged by officials. This suggests that crisis communication goals are achieved when the media is prepared the play the important role of reporting messages from the official source in the circumstances. In other words the narrower the gap between the messages from disaster managers and those presented by the media in their reports, the more successful the media management strategy. This also means that the distortion of information can be measured by the extent to which media reporting differs from the facts and perspectives of official sources managing the negative event.

As a guideline and blueprint for officials to respond quickly and to convey accurate and credible information to stakeholders in crisis situations, the Crisis and Emergency Risk Communication Framework (CERC) was developed by the Centre for Disease Control and Prevention (CDC) in the United States as tool specifically for communication responses in a crisis (Rickard et al, 2013). The CERC model defines a crisis as progressive and ongoing, involving the need for responses at three distinct stages described as the pre-crisis, crisis and the post-crisis. The underlying premise of the CERC model is for 'quick, accurate and credible communication responses in instances of high uncertainty as the crisis evolves. CERC emphasises the importance of officials establishing a close relationship with stakeholders, in particular journalists who are likely to report on the crisis and the overall management undertaken by officials. This close partnership should be fostered as part of the overall planning for crisis so that there is a framework of trust, networking and collaboration among credible sources to provide consistent messages to facilitate a speedy recovery from a crisis (Ricard et al, 2013).

According to Dunne (2004), media activity varies according to the various stages in a crisis. He suggests that the first stage of any crisis is known as the vacuum. This is the 
point when a disaster situation is developing or has just happened. Here there is much speculation and the potential for inaccurate information being disseminated is most acute. At this stage the media searches for as many sources as possible to locate any information with little regard for authoritativeness. Dunne argues that this is the stage where the 'seeds for recovery' are being sown. At stage two, the details of the crisis are now more clearly known and the media now train their focus mainly on the crisis and how it is being managed. For tourism destinations, Dunne notes that this stage may have the greatest impact where the travelling public may be assessing and making their decisions regarding existing and future travel plans.

At stage three, the recovery period, the hard news media has lost interest in the crisis and so the visitor mind set of the destination may be still at point of the first stage of information distortion and speculation. According to Milo and Yoder (1991), this is the point where the role of the travel writer is very critical in maintaining coverage of the destination by updates and reports of the restoration of infrastructure, civil order as well as tourist facilities. Prospective travellers in the information search stage of the tourist decision making process are likely to find more discerning and detailed information from the travel writers that is not as sensationalised and are more likely to reduce the level of uncertainly or risk with regard to travelling to the destination (Yoder and Milo: 1991; Nielsen: 2003).

So a distinction can be made between the framing strategies of the hard news press and the travel press as the various stages of the crisis evolves. While the hard news story writer may prioritise the currency of the unfolding events of the crisis in terms of a more catholic coverage, the travel press will tend to focus more on specific details of tourist infrastructure and amenities in terms of the overall recovery plans for the tourism sector. The travel specialist media will also seek to highlight the promotional and marketing activities that are employed by the destination as part of the overall recovery strategy.

\section{The Media and Travel Decision Process}

In the aftermath of a cataclysmic event at a destination, prospective travellers are likely to make a more detailed and extensive information search before making their decision to go there (Law:2006). More importantly, negative events may lead to changes in the 
assessment criteria in the purchase decision process (Glaesser, 2003:35). This means that certain destinations that may have been included in the evoked set of options for satisfying a need may be eliminated from this category depending on the nature of the coverage of the crisis or other variables such as the views of opinions leaders and word of mouth from personal sources that are associated with the crisis event. In such instances where negative events heighten the perceptions of risk, the tourist may seek out more detailed information, personal endorsements and recommendations in response to the dissonance that they are likely to experience in these circumstances.

It is in these moments of information search by the consumer that the media is most influential in shaping the attitudes and opinions of consumers and their related travel behaviour. However, while the mass media may shape opinions and strengthen existing attitudes, mass media output by itself does not fully explain and account for the consumer decision process. There is a complex web of interrelated variables that are involved in the travel decision process. Nevertheless, the significance of the media's role is that the information presented is appropriated and processed by the consumer in making the travel decision. Media messages therefore represent verbal and non-verbal stimuli to consumers that help to create the ideas and perceptions that constitute the organic image that they may have of the destination region. The nature of the coverage by the media of the negative event with respect to the sources they choose to quote, their news values in terms of prioritising and emphasis, all combine to construct a context of the risk associated with travel to the affected destination.

In the event that consumer risk and vulnerability are heightened by the nature and level of the media's general framing of the event, tourist authorities and destination managers face a more challenging task to rebuild consumer confidence. In the short term, intensive marketing and promotional activities as well as advertising spend are likely to increase to respond to the level of risk amplification presented by the news stories of the crisis. The higher the level of information distortion, the greater the need for more extensive, intensive and perhaps costly marketing strategies to redress the increased level of dissonance that may be associated with the destination in the major markets. In the short term, the main focus may be directed at maintaining market share and not losing too much ground in the marketplace. In the longer term, the main goals should be to maintain tourist arrivals without resorting to protracted periods of heavy 
discounting that may ultimately reduce and denigrate the value and brand image of the destination in the minds of consumers.

\section{Source Credibility}

Milo and Yoder (1991) noted that travel writers indicated their preference for the local tourist authority for the main source for information if they were to write a post quake story on San Francisco. They observed that in contrast, hard news story reporters tended to seek out authoritative sources backed up by their 'personal surveys of damaged areas'. This suggests that the news values and styles of hard news reporters and travel writers differ, in that travel writers tend to accept the credibility of tourism officials as key informants, while hard news reporters preferred to quote more highly ranked government officials as well as eyewitness accounts of people who experienced the event first-hand. These sources are deemed to be more suitable in relation to the news values of hard news reporting over the specialist reporting activities of the travel press (Hanusch, 2010). However, the media are likely to seek out sources that they believe have the authority and knowledge of the environment to assure their audience of their credibility and the veracity of their reports.

According to Lombardi (1995) the public perception of the credibility of the various informants and sources vary. Using three criteria of clarity of message, authority to give information and credibility and trustworthiness, Lombardi found that residents living in a high risk industrial town in Italy ranked scientist/technicians as the key information sources that locals would most prefer to inform them about industrial risks in their area. When ranked in order of preference, other sources identified were civil defence, Ministry of the Environment, environmental protection association, public health services, journalists and ecological groups. The least preferred sources were politicians, the army and consumer protection organisations. These findings suggest the public may have perceptions of credible sources that may differ from that of the media and also disaster management officials. However, the importance of source attribution in press accounts is emphasised by Milo and Yoder (1991) who also assert that the question of 'who serves as writers' sources' is crucial in determining the most effective crisis communication strategies'. 
Destination image formation theorises that consumers tend to rate information emanating from independent sources such as the media and word of mouth endorsements as being more credible than overt information from tourist boards and related advertising and public relations companies (Gartner, 1993; Hanusch, 2010; Nielsen: 2003). This means that the public will evaluate the credibility of the sender of the information as part of the cognitive processing of the media message. News reports also give an indication of their news values in terms of the sources they tend to choose as key informants for their news stories. The main sources used in their reports gives an indication of the media's as well as their audience's likely attribution of their credibility. Furthermore, the extent to which the media relies on official sources and attributes them in news coverage, may also demonstrate their engagement with official messages and their willingness to endorse their position on the negative event.

\section{Study Method}

This paper is an exploratory research on the representations and framing of tourist risk in press accounts in the UK newspapers. The Lexis Nexis search engine was used to retrieve articles on Hurricane Ivan that were published in the UK press. Thirteen newspaper titles were purposively selected to represent a mix of broadsheet and tabloid UK national newspapers. The keywords Hurricane Ivan were used to retrieve articles from September 6, 2004, with the approach of the hurricane to the region, to September 15 when it had moved away. This yielded some 62 articles that were content analysed using a coding instrument that identified the manifest variables which were the newspaper title of each article, the page of the story and the date when it was published. Also coded were four variables or latent variables that were less descriptive and required more subjective evaluation by the coders. These were 'type of story', whether news or travel, 'destination mention in headline', 'first attributed source(s)/ mentioned', and the 'focus of the lead sentence'.

INSERT TABLE 1 HERE

Table 1:- Example of Percentage Agreement between coders for key variables

\begin{tabular}{|l|l|l|l|}
\hline Variables & Coder A & Coder B & Agree (A) or Disagree (D) \\
\hline Type of Story & 2 & 2 & Agree \\
\hline Focus of Story & 3 & 3 & Agree \\
\hline $\begin{array}{l}\text { Destination(s) Men- } \\
\text { tion in Headline }\end{array}$ & Yes & \multicolumn{1}{|c|}{ Yes } & Agree \\
\hline
\end{tabular}




\begin{tabular}{|l|l|l|l|}
\hline $\begin{array}{l}\text { Destination(s) Men- } \\
\text { tioned negatively }\end{array}$ & 7 & 2 & Disagree \\
\hline $\begin{array}{l}\text { First source Men- } \\
\text { tioned }\end{array}$ & 5 & 5 & Agree \\
\hline Focus of lead sentence & 4 & 4 & Agree \\
\hline \multicolumn{1}{|l|}{ Total }
\end{tabular}

Percentage Agreement:- $\quad 5 / 6 \times 100=83 \%$

As indicated in the coding instrument presented in Table 1, hard news stories were differentiated from travel stories by the variable measuring 'type of story', while 'destination mention in the headline of story' recorded instances where particular destinations were highlighted as being affected by the hurricane. The 'first information source(s)' noted in each article was also coded. This was based on the list proposed by Lombardi (1995:7) which was modified to reflect the key informants relevant to the context of Hurricane Ivan. Some 12 categories were identified in this item on the coding form. The 'focus of lead sentence' variable attempted to identify the emphasis of the first line of the newspaper stories as an indicator of news saliency and framing strategy. For the purposes of this exploratory study, simple frequency counts and cross tabulations were undertaken using SPSS to generate descriptive statistics.

\section{Pre-test and Inter-coder-reliability}

The coding instrument for the study was pre-tested on a sample of three news articles in order to determine the suitability and applicability of the variables to be coded. Based on the pre-test, for the category 'first information source', the variable 'None' was added to reflect the fact that some articles did not mention any information source in the stories.

A sub-sample of six articles was purposively selected to determine the level of agreement between the two coders who independently coded these reports. Neuendorf (2002:159) recommends that for the reliability subsample, in order 'to ensure that the occurrence of key characteristics are in the reliability check, it may be necessary to purposely select units for reliability tests'.

Inter-coder reliability tests were conducted only on the latent variables which required more subjective assessment by coders as these variable required some level of interpretation in comparison to the more descriptive, manifest variables ( Lombard et 
at, 2002:589). These four variables tested were 'type of story', 'destination(s) mention in headlines', 'first source of information mentioned' and 'focus of lead sentence'. According to Neundorf (2002: 150) both percentage agreement as well as further tests to 'correct the role of chance agreement between coders' should be conducted for content analysis studies. Table 2 indicates both the percentage agreement and Scott's Pi for the four latent variables of the study. This calculation was done using ReCal2 which is an accredited online package that 'calculates several indices for nominal level variables' (Lombard et al, 2004; Freelon, 2010: http://www.ijis.net/ijis5 1/ijis5__ freelon_pre.html).

\section{PLACE TABLE 2 HERE}

Table 2

Press stories of Hurricane Ivan published in selected UK newspapers Sept 6-15, 2004

\begin{tabular}{|l|r|r|}
\hline \multicolumn{1}{|c|}{ Newspaper } & Frequency & Percent \\
\hline Sun Telegraph & 1 & 1.6 \\
Daily Telegraph & 10 & 16.1 \\
The Observer & 4 & 6.5 \\
The Guardian & 6 & 9.7 \\
Independent on & 2 & 3.2 \\
Sunday & 6 & \\
The Independ- & 2 & 9.7 \\
ent & 6 & 3.2 \\
Mail on Sunday & 1 & 9.7 \\
The Daily Mail & 9 & 1.6 \\
Sunday Express & 2 & 14.5 \\
The Express & 8 & 3.2 \\
The Sunday Ex- & 5 & 12.9 \\
press & 62 & 8.1 \\
The Mirror & & 100.0 \\
Daily Star &
\end{tabular}

There was a relatively low inter-coder reliability score for the variable 'type of story 'with a percentage agreement of $66.7 \%$ and Scott's Pi.at 0.2 . As this was a low level of agreement, it was concluded that this study was not able to distinguish clearly between hard news and travel stories. However, the variable, 'destination in headline' recorded $100 \%$ agreement between the coders. The two other variables, 'first information source' and 'focus of lead sentences' recorded high percentage scores of $83.3 \%$ and inter-coder agreement of 0.91 for Scott's Pi respectively. 


\section{Findings and Analysis}

The Daily Telegraph had the most number of articles with ten stories while the Sunday Express had the least number of only one story in the sample. For the upmarket prestige daily broadsheets such as the Daily Telegraph there were ten published articles while The Guardian and the Independent generated some six articles each, during the 10-day period covered by this study. The mid-market Express and the Daily Mail published some nine and six articles respectively, while the tabloid Mirror published eight and the Daily Star some five articles on Hurricane Ivan.

\section{PLACE TABLE 3 HERE}

Table 3

\section{Story Sources}

\begin{tabular}{|c|c|c|}
\hline Sources & Frequency & Percentage \\
\hline Weather experts & 7 & 11.3 \\
\hline Command centre & 5 & 8.1 \\
\hline Local politicians & 11 & 17.7 \\
\hline $\begin{array}{l}\text { Local tourist au- } \\
\text { thority }\end{array}$ & 1 & 1.6 \\
\hline $\begin{array}{l}\text { Travel intermedi- } \\
\text { ary }\end{array}$ & 8 & 12.9 \\
\hline Civil authorities & 2 & 3.2 \\
\hline $\begin{array}{l}\text { Eyewitnesses-tour- } \\
\text { ists }\end{array}$ & 6 & 9.7 \\
\hline $\begin{array}{l}\text { Local eyewit- } \\
\text { nesses }\end{array}$ & 5 & 8.1 \\
\hline $\begin{array}{l}\text { Journalists/news } \\
\text { services }\end{array}$ & 5 & 8.1 \\
\hline $\begin{array}{l}\text { Foreign Office/in- } \\
\text { ternational politi- } \\
\text { cians }\end{array}$ & 3 & 4.8 \\
\hline Other & 6 & 9.7 \\
\hline None & 3 & 4.8 \\
\hline Total & 62 & 100.0 \\
\hline
\end{tabular}

Generally, there were no significant differences between the various newspaper publications in terms of the sources of news stories and the thematic focus of the lead sentences. This suggests that regardless of market segments, UK newspapers tend to display similar news values in terms of framing and representations of the hurricane. This may imply that dominant framing strategies tend to supersede differences between the various market segments that these markets target for the consumption of their 
product. There is a danger is assuming that top UK newspaper brands would differ significantly in framing strategies than red top tabloids that are more renowned for their penchant for sensationalism. Despite the clear distinctions between the newspaper brands, these findings suggest that they share common news values and framing strategies in their coverage of Hurricane Ivan. This means that communication crisis managers can frame generic messages for the UK market based on the knowledge of the framing strategies that the media are likely to adopt.

For the variable, 'Destination mention in Headline' as indicated in Table Two, 62.9\% of articles did not name the destination in the headline of the article. This suggests that it is less likely for the destination brand name to be prominently associated with the Hurricane. In many respects this is beneficial for destinations experiencing a negative event not only because some persons only scan headlines of news stories, but also because headline mention tend to prelude the focus of the story in terms of an association between the risk and the country named.

\section{Story Sources}

Local politicians were the first attributed sources for stories in most articles at $17.7 \%$, with travel intermediaries such as tour operators coming in second at $12.9 \%$, and weather experts in third at $11.3 \%$. Tourists giving eyewitness accounts were popular sources for information for most newspapers at $9.7 \%$, with local eyewitnesses coming next at $8.1 \%$. 


\section{PLACE FIGURE 1 HERE}

Figure 1 - Focus of lead sentences

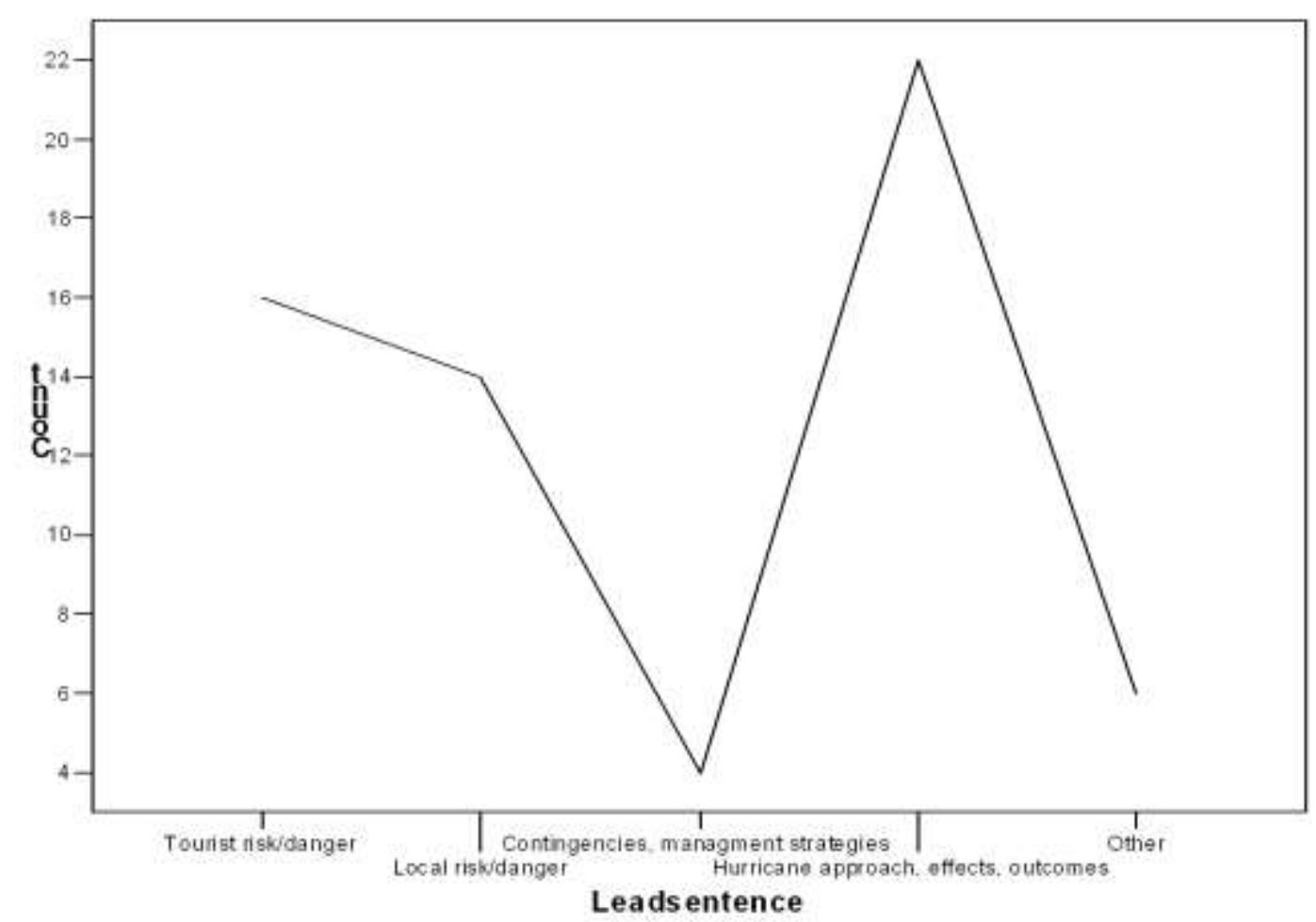

Expectedly, stories that used travel intermediaries and tourists who witnessed the hurricane as the first attributed source for information tended to have lead sentences that focused on tourist risk. Where local politicians were the main source of information, the lead sentences tended to emphasise risk to locals rather than tourists. Reports quoting weather experts as the first source of information in the story tended to highlight the approach of the hurricane, with a focus on describing its impact, effects and outcomes.

The approach of the Hurricane Ivan, as well as descriptions of its impacts and outcomes topped the list for the main lead sentence and focus for most newspaper stories. However, positioned second in frequency was the number of lead sentences that focussed on tourist risk with local risk coming next in line. Notably in spite of the extensive coverage of tourist related activities, local tourist authorities were firstly 
attributed as the information source only once in the entire sample. It is apparent that tourist authorities were not highly ranked in terms of credibility in providing information on tourists in a crisis. This may also reflect journalists' perceptions of the views of their readership who may not regard tourist agencies as independent, reliable sources of information. In contrast, tourism intermediaries operating in the UK tended to be more valued as the main sources for information for the press.

Destination managers may therefore need to engage travel intermediaries more in disaster management planning and operations so that they have awareness and a stake in these activities. It should not simply be a matter of airlifting tourists out in time in emergency situations, but also being able to acquaint the media with the overall disaster management activities that are taking place at the destinations and noting their specific role in the process. In this way, travel intermediaries, as the first source of information for news gatherers on the fate of tourists in these countries, may be able to start sowing the 'seeds of recovery' as noted by Dunne (2004) in the early stages of the crisis. However, such a partnership is only possible if travel intermediaries do not pursue short-term goals to exploit the disaster to procure heavy discounting from local tourism interests post disasters. Significantly, these findings point to the efficacy of the CERC model in advocating collaboration between stakeholders and with the media from the pre-crisis stage to establish trust. But ironically, they also suggest that travel intermediaries that were more likely to be the one of the leading sources of information, were associated with the amplification of tourist risk in the press stories.

\section{PLACE BAR CHART 1 HERE}

This bar chart shows that management strategies or measures to mitigate the impending or unfolding crisis are rarely accorded much saliency in the news coverage of the hurricane. Only four lead sentences in 62 articles focussed on these measures. Stories were therefore mainly framed in terms of the description of the hurricane often attempting to enact or stage the event for readers. This framing strategy tended to heighten and amplify the danger and risk of locals and tourists at the destination. More importantly, this type of framing heightened public risk perception by presenting a scenario of helplessness of people being overwhelmed with little course of action or 
redress in the face of inevitable disaster. Often, crisis plans were in place and were being executed, but this distortion of the events taking place at the destination, tended to amplify risk and provide readers with little information as to what opportunities were available to mitigate the danger of the situation. According to Lombardi (1995:11), this poses the problem of 'information catastrophe' when the media not only functions as 'the instrument of propagation but is also the main factor that determines the perception and definition of the event itself'.

Lombardi (1995) suggests that information command centres that have the status of official sources of information may redress information distortion by putting out for all stakeholders 'reliable, unambiguous and clear messages' that serve to expose myth, fallacies and misrepresentations that may be purveyed by some news agencies. Specific, directed information and practical advice to tourists on how to reduce risk in situations of crisis may serve to reduce risk perception and allow them to cognitively focus on ways and means to mitigate danger in such circumstances (Lundgren \& McMakin, 2013).

Nevertheless it takes more than the centralisation and control of information on disasters to counter framing strategies that heighten or distort risk perception. It is also important to continue to examine these patterns of representation and 'meaning making' in order to devise effective crisis communication strategies for destinations that experience negative events.

\section{Conclusion}

One of the ways tourism officials of destinations affected by the 2004 Indian Ocean Tsunami were able to stem overwhelming images and impacts of the disaster was to encourage the public to contribute to the rebuilding of these devastated regions by visiting the countries. This approach had the support of tour operators and tourism advocacy organisations in an attempt to restore these destinations to normality after the crisis. The United Nations World Tourism Organisation (UNWTO) launched an awareness campaign dubbed 'Holiday with your heart- travel to Sri Lanka, Maldives, Thailand and Indonesia' to tell 'another story' of tourism recovery in the region. The extent of the strategy to encourage tourist visits post tsunami, thereby successfully limiting the length of the recovery period for the tourism industry is not clearly 
indicated in the literature. Nevertheless, is may be plausible that encouraging tourists to visit the affected areas served to highlight the fact that the effects of the disaster were being managed even though coverage of the aftermath of the tsunami were continuing.

This notion of management, contingencies and control are key factors in reducing perceptions of tourist risk. As identified by the findings of this study, the framing strategies of Hurricane Ivan by the UK press did not attribute much salience to efforts to reduce the risks, even though they may have used disaster managers as their main sources for information. Instead, framing strategies mainly focussed on enacting the hurricane, describing its approach and in emphasising the risk to tourists and locals. Even though Hurricane Ivan was an 'escapable disaster' with planned disaster management measures which were in place and executed, yet the predominant media framing was to represent the natural disaster mainly in terms of discourses relating to those that were sudden, and catastrophic with not much lead time to implement disaster management plans (Huan, et al, 2004). Consequently, as the findings indicate, overall UK press reports tended to amplify rather than to attenuate tourist risk.

It may therefore not be enough for crisis communication managers to send messages to the media that only seek to describe issues related to managing the event (Choi \& Lin, 2008). Ironically, too much emphasis on safety can have the opposite effect of prompting reporters to search for instances that discount this notion of safety, and also to reinforce the fact to consumers that a dangerous situation may have been or may be still unfolding. However, counter strategies could involve more monitoring and examination of typical media framing, and then developing messages that may neutralise them by providing alternative frames or ways of seeing the crisis that are reoriented towards the execution of the management plan.

Tourist dependent regions such as the Caribbean and the US state of Florida that have faced the perils of many hurricanes in the past can be credited for having developed marketing expertise and savvy to respond to related disasters. As reported by Pratt (2003), post 9/11, Bahamas and Jamaica responded promptly by putting in place emergency marketing funds to implement advertising and promotional activities to redress the heightened risk associated with travel. One year later, both the Bahamas and Jamaica were reporting almost full recovery after the event. Still, while such trade 
and consumer marketing initiatives are invaluable, more attention must be paid to the wider, holistic images of the destination that may be affected by press reporting after negative events. Indeed, counter strategies will in many ways be prescriptive in providing an operations manual based on best practice and experience (Rickard et al, 2013). Nevertheless, there is also the need to monitor the environment more closely in terms of press activity, in order to devise creative and dynamic emergent crisis communication strategies to reduce heightened perceptions of tourist risk.

Long term sustainability of tourism destinations post negative events are not entirely resolved by throwing large sums of marketing funds to fire-fight the crisis. The most lasting negative impact to a country's sustainability in the aftermath of a disaster is the inability to rebuild brand status, or to credibly convey a trusted and valued brand. Pursuing a simultaneous strategy to discount prices and also to advertise at the same time may be inimical to the long term positioning of the destination. Ultimately, the attrition in brand value for the destination that may have occurred through negative press accounts, may be reflected in the steadily increasing, more expensive marketing and promotions spend in successive years.

\section{Future of tourism crisis communications}

As the new frontline of communications, social media have emerged as a premier means and source of information. Future research on constructions of tourist risk post disasters should therefore include the wide spectrum of social media in order to reflect their role and significance in today's communication processes (Fisher Liu \& Jin, 2011) . However, while the media landscape is becoming even more complex and unpredictable with the emergence of new and diverse range of communication technology, nevertheless the focus of tourism marketers should be on how to harness these means to redress media distortion and amplification of the crisis event as it unfolds at the destination (Rickard et al, 2013).

In terms of bolder, innovative strategies in the long term, it may be necessary to engage in year round communications that incorporate and frame new discourses of travel that focus on the possibilities of tourists managing risk as part of the experience of a hedonistic, pleasurable activity of a holiday. This may not be too far-fetched since the notion of travel has evolved from the root word 'travail' implying that there is some 
risk involved in the travel experience. Essentially such marketing messages could effectively reduce tourist risk by communicating that tourism can still can be pursued as long as individuals are aware of the risks, and have sufficient know-how on how to manage and mitigate them. Even as the frontiers of space travel are opening up, its associated risks as an opportunity for a thrilling, yet pleasurable vacation experience are arguably becoming normalised. This may suggest that as Smallman (1997) has contended, that although the world is perceived as becoming a more 'riskier place', it may very well be that new perceptions of travel are also being socially constructed to accommodate this awareness of risk as part of the experience. It is as these constructs are studied and examined more closely, that tourism crisis communications strategies may become even more effective in managing tourists' perceptions of risk.

\section{REFERENCES}

Ashcroft, Linda S.(1997) 'Crisis Management-pubic relations'. Journal of Managerial Psychology 12 (5) 325-332.

Avraham, Eli and Ketter, Evan (2008) Media Strategies for Marketing Places in Crisis. Oxford: Butterworth-Heinemann.

BBC (2004) 'Grand Cayman disorder after Ivan' . Thursday, 16 September, 2004. Available at: http://news.bbc.co.uk/1/hi/uk/3663608.stm. Date accessed: 10/08/2012.

Bierman, David (2003) Restoring Tourism Destinations in Crisis- A strategic marketing approach'. Australia: Allen \& Unwin.

Choi Yoonhyeung,; Lin, Ying-Hsuan (2008) 'A content analysis of the newspaper coverage of the three major hurricanes in 2005'. Public Relations Review 34 (3) 294-296. 
Dfreelon.org ReCal2: Reliability for 2 Coders

Available at: http://dfreelon.org/utils/recalfront/recal2/\#doc. Date accessed: 29/05/14.

Dunne, Steve (2004) 'Crisis Communication: Who should I really be talking to?' Paper presented at First International Conference on Tourism Communications, Madrid, Spain.

Faulkner, Bill (2001) 'Towards a framework of tourism disaster management'. Tourism Management 22 (1) 135-147.

Freelon, D. (2010). ReCal: Intercoder reliability calculation as a web service. International Journal of Internet Science, 5(1), 20-33.

Fisher Liu, B; Austin, L.; Jin, Y. (2011) 'How publics respond to crisis communication strategies: The interplay of information form and source'. Public Relations Review 37 (4) 345-353.

Gartner, William (1993) 'Image Formation Process'. Journal of Travel \& Tourism Marketing 2 (2/3) 191-215.

Glaesser, Dirk (2003) Crisis Management in the Tourism Industry. Oxford, Butterworth-Heinemann.

Gonzalez-Herrero and Pratt, Cornelius B. (1998) 'Marketing Crises in Tourism: Communication Strategies in the United States and Spain'. Public Relations Review 24 (1) 83-97.

Goodman, Michael B. (2001) 'Current trends in corporate communication'. Corporate Communications: An International Journal 6 (3) 117-123.

Hanusch, Folker (2010) 'The Dimensions of Travel Journalism'. Journalism Studies 11 (1) 68-82.

Henderson, Joan C. (2000) 'Communicating in a crisis: flight SQ 006' Tourism Management 24 (1) 279-287.

Huan, Tzung-Chen; Beaman, Jay; Shelby, Lori (2004) ' No-Escape Natural Disaster Mitigating Impacts on Tourism'. Annals of Tourism Research 31 (2) 255-273.

Kasperson, J.X. and Kasperson, R.E. (2005) The Social Contours of Risk. Publics, Risk Communication and the Social Amplification of Risk. Volume 1. London: Earthscan.

Law, Rob (2006) 'The Perceived Impact of Risks on Travel Decisions'. International Journal of Travel Research 8 (2) 289-300.

Lombard, M; Synder- Duch, J; Campanella Braken, C. (2002) 'Content Analysis in Mass Communication: Assessment and Reporting of Intercoder Reliability'. Health Communication Research 28 (4) 587-604. 
Lombard, M; Synder-Duch, J; Campanella Braken, C. (2004) Practical Resources for Assessing and Reporting Intercoder Reliability in Content Analysis Research Projects http://matthewlombard.com/reliability/\#What is intercoder reliability

Lombardi, Marco (1995) 'Communication about major accident hazards: credibility of qualified informers in an Italian city'. Disaster Prevention and Management 4 (2) 4-13.

Lundgren, R.E and McMakin, A.H. (2013) Risk Communication: A Handbook for Communicating Environmental, Safety and Health Risks. Piscataway, New Jersey: IEEE Press, Wiley.

Milo, Katerine Jean and Yoder, Sharon (1991) 'Recovery from Natural Disaster: Travel Writers and Tourist Destinations' Journal of Travel Research (30) 136-39.

Nielsen, Christian (2001) Tourism and the Media. Australia: Hospitality Press Pty.

Neuendorf, Kimberly (2002) The Content Analysis Guidebook. Thousand Oaks, Sage Publications Inc.

Pidgeon, N.; Kasperson, R.; Slovic, P. (eds) (2003) The Social Amplification of Risk. Cambridge: Cambridge University Press.

Pratt, Godfrey (2003) 'Terrorism and tourism: Bahamas and Jamaica fight back'. International Journal of Contemporary Hospitality Management 15 (3) 192-194.

Reisinger, Y. and Mavondo, F. (2005) 'Travel anxiety and intentions to travel internationally'. Journal of Travel Research 43 (1) 212-225.

Rickard, L.N; McComas, K.A.; Clarke, C.E.; Stedman, R.C; Decker, D.J. (2013) 'Exploring risk attenuation and crisis communication after a plague death in Grand Canyon'. Journal of Risk Research 16 (2) 145-167.

Ritchie, Brent W. (2004) 'Chaos, crises and disasters: a strategic approach to crisis management in the tourism industry’. Tourism Management 25 (1) 669-683.

Santos, Carla Almeida (2004) 'Framing Portugal: Representational Dynamics' Annals of Tourism Research 31 (1) 122-138.

Smallman, Clive (1997) 'Read all about it - risk trends in the media: a research note'. Disaster Prevention and Management 6 (3) 160-164.

Smallman, Clive and Weir, David (1999) 'Communication and cultural distortion during crises'. Disaster Prevention \& Management 8 (1) 33-41.

Stafford, Greg, Yu, Larry, Armoo, Alex (2002) 'Crisis Management and Recovery How Washington, DC Responded to Terrorism'. Cornell Hotel and Restaurant Administration Quarterly October, 27-40. 
Zerman, David (1995) 'Crisis communication: managing the mass media'. Information Management Computer Security 3 (5) 25-28. 